\title{
Preoperative atrial fibrillation portends poor outcomes after coronary bypass graft surgery: A systematic review and meta-analysis
}

\author{
Akshat Saxena, MBBS, BMedSc, MS, ${ }^{\text {a,b }}$ Sohaib A. Virk, BMed/MD, BSc(Med), \\ Sebastian Bowman, BMedSc, ${ }^{\mathrm{c}}$ Lionel Chan, MBBS, PhD, ${ }^{\mathrm{a}}$ Richmond Jeremy, MBBS, PhD, ${ }^{\mathrm{e}}$ and \\ Paul G. Bannon, MBBS, PhD ${ }^{\mathrm{a}, \mathrm{b}, \mathrm{d}}$
}

\begin{abstract}
From the Departments of a Cardiothoracic Surgery and ${ }^{\mathrm{e}}$ Cardiology, Royal Prince Alfred Hospital, Sydney, Australia; and ${ }^{\mathrm{b}}$ The Baird Institute, Sydney, Australia; ${ }^{\mathrm{c}}$ Melbourne Medical School, University of Melbourne, Melbourne, Australia; and ${ }^{\mathrm{d}}$ Institute of Academic Surgery, The University of Sydney, Sydney, Australia. Received for publication July 5, 2016; revisions received Oct 30, 2017; accepted for publication Nov 16, 2017. Address for reprints: Paul G. Bannon, MBBS, PhD, Department of Cardiothoracic Surgery, Royal Prince Alfred Hospital, Missenden Rd, Camperdown, NSW 2050, Australia (E-mail: pgbannon@gmail.com).

J Thorac Cardiovasc Surg 2018;155:1524-33

$0022-5223 / \$ 36.00$

Copyright (C) 2017 Published by Elsevier Inc. on behalf of The American Association for Thoracic Surgery https://doi.org/10.1016/j.jtcvs.2017.11.048
\end{abstract}

Supplemental material is available online.

$\rightarrow$ Video clip is available online.

Atrial fibrillation (AF) is the most common abnormal cardiac rhythm, with an estimated prevalence of $4 \%$ in the Australian population older than the age of 30 years. ${ }^{1}$ The incidence of AF steadily increases with age; the prevalence in those older than 80 years is up to $15 \%$. The loss of coordinated atrial activity by AF predisposes patients to thrombus formation and, subsequently, embolic stroke. ${ }^{3}$ Moreover, chronic AF has been associated with a 2-fold increase in the risk of premature death. ${ }^{3}$

The demographic profile of patients undergoing coronary artery bypass graft (CABG) surgery has significantly changed in the past 2 decades as the result of an increased use of coronary stents and the aging population of developed countries. Increasingly, older patients with a greater incidence of comorbidities including valvular disease, diabetes, and impaired ventricular function are undergoing $\mathrm{CABG}^{4-6}$ These factors are all associated with an increased risk of $\mathrm{AF}^{7}$ Hence, it is imperative to understand the clinical implications of preoperative atrial fibrillation (preAF) for patients undergoing CABG. Some cohort studies have demonstrated that preAF may be an independent risk factor for poorer perioperative outcomes and reduced long-term survival. ${ }^{8-12}$ However, there has only been a limited evaluation of preAF in the context of CABG surgery, and the EuroSCORE has not recognized preAF as a risk modifier. Moreover, the impact of preAF on clinical outcomes according to revascularization strategy (on-pump or off-pump CABG) remains largely unexplored.

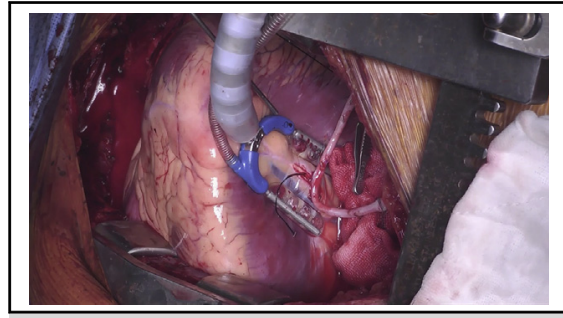

Off-pump coronary artery bypass graft (OPCAB) surgery of the inferior wall.

Central Message

Preoperative atrial fibrillation portends poorer outcomes in patients undergoing CABG, regardless of revascularization strategy.

\section{Perspective \\ Atrial fibrillation (AF) is present in up to $10 \%$ of patients undergoing CABG surgery. There is uncertainty about the prognostic implications of $\mathrm{AF}$ in patients undergoing $\mathrm{CABG}$. Our study demonstrates, through a meta-analysis, that $\mathrm{AF}$ portends poorer early and late outcomes after CABG.}

See Editorial Commentary page 1534.

See Editorial page 1522.

The primary aim of this of this meta-analysis was to evaluate the impact of preAF on short- and long-term outcomes after CABG surgery. As a secondary outcome, the impact of preAF on clinical outcomes depending on revascularization strategy (on-pump vs off-pump) was explored. Our hypothesis is that preAF has a negative impact on early and late outcomes after CABG surgery.

\section{METHODS}

This systematic review and meta-analysis was conducted and presented in accordance with the Preferred Reporting Items for Systematic Reviews and Meta-Analyses guidelines. ${ }^{13}$ The study was approved by the local ethics committee.

\section{Search Strategy and Study Selection}

Electronic searches were performed with Ovid Medline, Embase, and Cochrane Central Register of Controlled Trials from their dates of inception to January 2016. The search terms "coronary artery bypass" 
TABLE 1. Summary of study characteristics

\begin{tabular}{|c|c|c|c|c|c|c|c|c|}
\hline & \multirow[b]{2}{*}{ Study Period } & \multirow[b]{2}{*}{ Institution } & \multirow{2}{*}{$\begin{array}{l}\text { Type of CABG } \\
\text { Surgery }\end{array}$} & \multirow[b]{2}{*}{ Study design } & \multirow[b]{2}{*}{ Follow-up, y } & \multicolumn{3}{|c|}{ Number of patients } \\
\hline & & & & & & $\mathbf{A F}$ & No AF & Total \\
\hline $\begin{array}{l}\text { Ad and } \\
\text { colleagues, } \\
2009^{17}\end{array}$ & $2002-2003$ & $\begin{array}{l}\text { Society of Thoracic Surgeons } \\
\text { National Adult Cardiac } \\
\text { Surgery Database }\end{array}$ & ONCABG & Retrospective OS & Perioperative & 15,755 & 265,814 & 281,569 \\
\hline $\begin{array}{l}\text { Al-Sarraf and } \\
\text { colleagues, } \\
2012^{9}\end{array}$ & 2000-2008 & St James's Hospital & ONCABG & Retrospective OS & Perioperative & 413 & 3364 & 3777 \\
\hline $\begin{array}{l}\text { Attaran and } \\
\text { colleagues, } \\
2011^{10}\end{array}$ & $2000-2010$ & $\begin{array}{l}\text { Liverpool Heart and Chest } \\
\text { Hospital }\end{array}$ & $\begin{array}{r}\mathrm{ONCABG}+ \\
\text { OPCABG }\end{array}$ & Retrospective OS & $10^{*}$ & 477 & 9984 & 10,461 \\
\hline $\begin{array}{l}\text { Banach and } \\
\text { colleagues, } \\
2008^{18}\end{array}$ & 2000-2004 & $\begin{array}{l}\text { Department of Cardiac } \\
\text { Surgery, Medical } \\
\text { University Lodz, } \\
\text { Poland }\end{array}$ & ONCABG & Retrospective OS & $3 *$ & 174 & 2826 & 3000 \\
\hline $\begin{array}{l}\text { Boning and } \\
\text { colleagues, } \\
2015^{19}\end{array}$ & 2008-2011 & Multicenter & $\begin{array}{r}\text { ONCABG + } \\
\text { OPCABG }\end{array}$ & Retrospective OS & Perioperative & 232 & 2071 & 2303 \\
\hline $\begin{array}{l}\text { Bramer and } \\
\text { colleagues, } \\
2010^{23}\end{array}$ & $1998-2007$ & $\begin{array}{l}\text { Catharina Hospital, } \\
\text { Eindhoven }\end{array}$ & ONCABG & Retrospective OS & $4.6 \pm 2.9$ & 221 & 8630 & 8851 \\
\hline $\begin{array}{l}\text { Fukahara and } \\
\text { colleagues, } \\
2010^{20}\end{array}$ & $2000-2005$ & $\begin{array}{l}\text { University of Toyama, } \\
\text { Japan }\end{array}$ & OPCABG & Retrospective OS & $3.3 \pm 2.7$ & 26 & 487 & 513 \\
\hline $\begin{array}{l}\text { Ngaage and } \\
\text { colleagues, } \\
2007^{8}\end{array}$ & 1993-2002 & $\begin{array}{l}\text { Mayo Clinic College of } \\
\text { Medicine }\end{array}$ & ONCABG & Retrospective OS & $6.7^{*}$ & 257 & 269 & 526 \\
\hline $\begin{array}{l}\text { O'Neal and } \\
\text { colleagues } \\
2013^{21}\end{array}$ & 2002-2011 & $\begin{array}{l}\text { East Carolina Heart } \\
\text { Institute }\end{array}$ & ONCABG & Retrospective OS & $4.2[1.85-6.55]$ & 263 & 5175 & 5438 \\
\hline $\begin{array}{l}\text { Quader and } \\
\text { colleagues, } \\
2004^{22}\end{array}$ & $1972-2000$ & $\begin{array}{l}\text { The Cleveland Clinic } \\
\text { Foundation }\end{array}$ & ONCABG & Retrospective OS & $12.6 \pm 7.3$ & 451 & 46,533 & 46,984 \\
\hline $\begin{array}{l}\text { Rogers and } \\
\text { colleagues, } \\
2006^{12}\end{array}$ & 1996-2002 & $\begin{array}{l}\text { Patient Activity Tracking } \\
\text { System Database }\end{array}$ & ONCABG & Retrospective OS & $5^{*}$ & 125 & 4917 & 5042 \\
\hline $\begin{array}{l}\text { Saxena and } \\
\text { colleagues, } \\
2015^{11}\end{array}$ & 2001-2009 & $\begin{array}{l}\text { Australasian Society of } \\
\text { Cardiac and Thoracic } \\
\text { Surgeons }\end{array}$ & ONCABG & Retrospective OS & $3.08+$ & 1312 & 20,222 & 21,534 \\
\hline
\end{tabular}

Data presented as mean \pm standard deviation or median [interquartile range], unless otherwise stated. $C A B G$, Coronary artery bypass graft surgery; $A F$, atrial fibrillation; $O N C A B G$, on-pump coronary artery bypass graft surgery; $O S$, observational study; $O P C A B G$, off-pump coronary artery bypass graft surgery. *Median. $\dagger$ Mean.

OR "CABG" were combined with "atrial fibrillation" AND ("baseline OR "pre-operative") as key words and Medical Subject Headings terms. This was supplemented searching the reference lists by hand of key reviews and all potentially relevant studies.

Two reviewers (A.S., S.A.V.) independently screened the title and abstract of records identified in the search. Full-text publications were subsequently reviewed separately if either reviewer considered the manuscript as being potentially eligible. Disagreements regarding final study inclusion were resolved by discussion and consensus.

\section{Eligibility Criteria}

Eligible studies were those reporting on clinical outcomes of isolated $\mathrm{CABG}$ according to the presence or absence of baseline AF. Both randomized controlled trials and observational studies were eligible for inclusion. Noncomparative studies lacking a control group of patients without preAF were excluded. Studies presenting mixed data for different cardiac surgeries were only included if clinical outcomes for the isolated CABG cohort were separately reported. Studies reporting outcomes of patients undergoing concomitant AF surgery were excluded.

All publications were limited to those involving human subjects and written in English. Abstracts, case reports, conference presentations, editorials, and expert opinions were excluded. Studies with fewer than 100 patients in either arm were also excluded. Review articles were omitted because of potential publication bias and duplication of results. When institutions published duplicate studies with accumulating numbers of patients or increased lengths of follow-up, only the most complete reports were included for quantitative assessment. 
TABLE 2. Baseline patient characteristics in studies examining impact of preoperative atrial fibrillation on outcomes after isolated coronary artery bypass grafting

\begin{tabular}{|c|c|c|c|c|c|c|c|c|}
\hline \multirow[b]{2}{*}{ Study } & \multicolumn{2}{|c|}{ Age } & \multicolumn{2}{|c|}{ Male } & \multicolumn{2}{|c|}{ Diabetes } & \multicolumn{2}{|c|}{ Previous MI } \\
\hline & AF & No AF & $\overline{\mathbf{A F}}$ & No AF & $\overline{\mathbf{A F}}$ & No $\mathbf{A F}$ & $\overline{\mathbf{A F}}$ & No AF \\
\hline Ad and colleagues, $2009^{17}$ & NR & NR & 72 & 72 & $38^{*}$ & $36^{*}$ & $53 *$ & $45^{*}$ \\
\hline Al-Sarraf and colleagues, $2012^{9}$ & NR & NR & NR & NR & NR & NR & NR & NR \\
\hline ONCABG & $70.1[64.8-74.9]$ & $70.4[65.5-75.0]$ & 89 & 89 & 26 & 25 & NR & NR \\
\hline OPCABG & $70.7[65.5-75.3]$ & $71.3[65.5-75.6]$ & 88 & 88 & 32 & 30 & NR & NR \\
\hline Banach and colleagues, $2008^{18}$ & $64.4 \pm 7.9^{*}$ & $59.7 \pm 9.5^{*}$ & $58^{*}$ & $70^{*}$ & $18^{*}$ & $15^{*}$ & NR & NR \\
\hline ONCABG & 78.8 & 78.4 & 70 & 67 & 18 & 14 & 39 & 38 \\
\hline OPCABG & 78.8 & 78.6 & 80 & 67 & 22 & 14 & 37 & 36 \\
\hline Bramer and colleagues, $2010^{23}$ & $69.8 \pm 7.8$ & $70.2 \pm 7.7$ & 76 & 74 & 24 & 19 & NR & NR \\
\hline Fukahara and colleagues, $2010^{20}$ & $69.9 \pm 10.1$ & $67.0 \pm 9.8$ & 85 & 78 & 8 & 14 & 35 & 40 \\
\hline Ngaage and colleagues, $2007^{8}$ & $71 \pm 8$ & $70 \pm 8$ & 79 & 79 & 35 & 26 & 55 & 52 \\
\hline O'Neal and colleagues $2013^{21}$ & NR & NR & NR & NR & NR & NR & NR & NR \\
\hline Quader and colleagues, $2004^{22}$ & $66.2 \pm 9.0$ & $66.6 \pm 9.0$ & 81 & 80 & 22 & 20 & 54 & 55 \\
\hline Rogers and colleagues, $2006^{12}$ & $68[64-73]^{*}$ & $64[57-70]^{*}$ & 85 & 81 & $24 *$ & $16^{*}$ & $53 *$ & $43^{*}$ \\
\hline Saxena and colleagues, $2015^{11}$ & $71.1 \pm 8.6^{*}$ & $65.2 \pm 10.5^{*}$ & 77 & 78 & 36 & 33 & $33^{*}$ & $25^{*}$ \\
\hline
\end{tabular}

Data presented as mean $\pm \mathrm{SD}$, median [IQR], or \% of patients. $M I$, Myocardial infarction; $P V D$, peripheral vascular disease; $C V D$, cerebrovascular disease; $L V E F$, left ventricular ejection fraction; $N Y H A$, New York Heart Association; $H T N$, hypertension; $A F$, atrial fibrillation; $N R$, not reported; $O N C A B G$, on-pump coronary artery bypass graft surgery; $O P C A B G$, off-pump coronary artery bypass graft surgery. $* P<.05$.

\section{Data Extraction and Quality Assessment}

All data were independently extracted from text, tables, and figures by 2 investigators (S.A.V. and S.B.). The final results were reviewed by the senior reviewer (A.S.). For each study, the following information was extracted: study period, institution, study design, patient characteristics and risk factors, procedural details, and clinical outcomes.

The predetermined primary endpoint was perioperative all-cause mortality, defined as death occurring within 30 days of surgery or during the same hospitalization. Secondary endpoints included perioperative morbidity (stroke, acute renal failure, myocardial infarction, wound infection, prolonged ventilation, reoperation for any cause, reoperation for bleeding, need for transfusion) and midterm survival. The definition of wound infection was inconsistent between studies; some studies reported on sternal wound infection, whereas others reported any surgical-site infection (eg, sternal and/or graft).

Study quality was assessed with the Newcastle-Ottawa Scale for cohort studies, which has established validity and is recommended by the Cochrane Collaboration. A maximum total of 9 points is possible over the areas of sample selection (0-4 points), comparability of cohorts (0-2 points), and outcome assessment (0-3 points), with a score greater than 5 indicating reasonable study quality.

\section{Statistical Analysis}

The odds ratio (OR) or hazards ratio (HR) were used as summary statistics, and reported with $95 \%$ confidence intervals (CIs). When available, multivariable adjusted or propensity-matched ratios were extracted from individual studies. Otherwise, unadjusted ratios were computed from the exposure distribution given in the papers.

Meta-analyses were performed with random-effects models (inverse-variance technique) to take into account he anticipated clinical and methodologic diversity between studies. The $\mathrm{I}^{2}$ statistic was used to estimate the percentage of total variation across studies due to heterogeneity rather than chance, with values exceeding $50 \%$ indicative of considerable heterogeneity. Subgroup analysis was conducted to specifically examine the impact of preAF on outcomes after conventional and off-pump CABG. Sensitivity analysis by study quality was conducted, excluding studies that did not report propensity-matched or multivariable adjusted ratios. In all manuscripts that were analyzed, the groups of stratified based on the presence or absence of preAF.

Publication bias was assessed by the use of funnel plots comparing log ORs with their standard error. Egger's linear regression method ${ }^{14}$ and Begg's rank correlation test ${ }^{15}$ were used to detect funnel plot asymmetry, and the Trim-and-Fill method was used to explore the impact of studies potentially missing due to publication bias. ${ }^{16}$ Statistical analysis was conducted with Review Manager Version 5.1.2 (Cochrane Collaboration, Software Update, Oxford, United Kingdom) and Comprehensive Meta-Analysis v2.2 (Biostat Inc, Englewood, NJ). All $P$ values were 2 sided, and values $<.05$ were considered statistically significant.

\section{RESULTS}

\section{Study Characteristics}

A total of 1105 unique records were identified through the database and bibliographic searches. After considerable filtering, 1024 were excluded on the basis of title and abstract content. After the full text of the remaining 81 articles was screened, 12 studies met the inclusion criteria. ${ }^{8-12,17-23}$

All included studies were retrospective observational reports (Table 1). These included data on a total of 389,998 patients who underwent CABG; 370,292 patients did not have preAF and 19,706 had preAF. The median study sample size was 5240 (range, 513-281,569). In 3 studies, outcome reporting was limited to the perioperative period. ${ }^{9,17,19}$ In the remaining studies, the mean or median follow-up time ranged from 3 to 12.6 years. All included studies had a Newcastle-Ottawa Scale score of at least 5, indicating good quality. Quality assessment scores for 
TABLE 2. Continued

\begin{tabular}{|c|c|c|c|c|c|c|c|c|c|}
\hline \multicolumn{2}{|c|}{ PVD } & \multicolumn{2}{|c|}{ CVD } & \multicolumn{2}{|c|}{ LVEF \% } & \multicolumn{2}{|c|}{ NYHA III/IV } & \multicolumn{2}{|c|}{ HTN } \\
\hline$\overline{\mathbf{A F}}$ & No $\mathrm{AF}$ & $\overline{\mathbf{A F}}$ & No $A F$ & $\mathbf{A F}$ & No AF & $\mathbf{A F}$ & No AF & $\overline{\mathbf{A F}}$ & No $\mathrm{AF}$ \\
\hline $23^{*}$ & $16^{*}$ & $21 *$ & $13^{*}$ & NR & NR & $66^{*}$ & $58^{*}$ & $81 *$ & $76^{*}$ \\
\hline NR & NR & NR & NR & NR & NR & NR & NR & NR & NR \\
\hline 17 & 18 & NR & NR & $15(<30 \%)$ & $14(<30 \%)$ & NR & NR & 69 & 68 \\
\hline 18 & 16 & NR & NR & $18(<30 \%)$ & $18(<30 \%)$ & NR & NR & 75 & 75 \\
\hline NR & NR & NR & NR & $39.4 \pm 6.7^{*}$ & $43.7 \pm 9.6^{*}$ & NR & NR & NR & NR \\
\hline 35 & 33 & 9 & 8 & $3(<30 \%) *$ & $7(<30 \%)^{*}$ & 55 & 42 & NR & NR \\
\hline 35 & 32 & 11 & 10 & $5(<30 \%)^{*}$ & $2(<30 \%)^{*}$ & 60 & 44 & NR & NR \\
\hline 15 & 15 & 8 & 11 & $33.5(<50 \%)$ & $30.8(<50 \%)$ & NR & NR & 48 & 41 \\
\hline 8 & 6 & 27 & 20 & $50.0 \pm 14.6^{*}$ & $56.1 \pm 12.2 *$ & NR & NR & 58 & 56 \\
\hline NR & NR & 11 & 10 & $53.0 \pm 14$ & $56.0 \pm 16$ & 92 & 87 & 74 & 71 \\
\hline NR & NR & NR & NR & NR & NR & NR & NR & NR & NR \\
\hline 27 & 28 & NR & NR & NR & NR & 39 & 38 & 73 & 74 \\
\hline $17 *$ & $9^{*}$ & $19^{*}$ & $8^{*}$ & $45(<50 \%)^{*}$ & $27(<50 \%)^{*}$ & $50 *$ & $34^{*}$ & $67^{*}$ & $58^{*}$ \\
\hline $18 *$ & $12 *$ & $17 *$ & $11^{*}$ & $8(<30 \%)^{*}$ & $4(<30 \%) *$ & $32 *$ & $21^{*}$ & $82 *$ & $77^{*}$ \\
\hline
\end{tabular}

individual studies are displayed in Table E1. Baseline demographic characteristics and risk-factor profiles of study participants are summarized in Table 2 .

\section{Clinical Outcomes}

Entire cohort. The impact of preAF on perioperative and late outcomes after isolated CABG is summarized in Table 3. There was a statistically significant association between preAF and perioperative mortality (OR, 1.64; 95\% CI, $1.29-2.09 ; P<.001 ; \mathrm{I}^{2}=54 \%$ ). PreAF was also associated with stroke (OR, $1.50 ; 95 \% \mathrm{CI}, 1.06-2.11 ; P=.02$; $\left.\mathrm{I}^{2}=63 \%\right)$, acute renal failure (OR, $1.50 ; 95 \%$ CI, 1.23 $\left.1.83 ; P<.001 ; \mathrm{I}^{2}=48 \%\right)$, prolonged ventilation $(\mathrm{OR}, 1.40$;
95\% CI, 1.16-1.68; $P<.001 ; \mathrm{I}^{2}=53 \%$ ), and reoperation for bleeding (OR, 1.22; 95\% CI, 1.07-1.40; $P=.003$, $\left.\mathrm{I}^{2}=19 \%\right)$. PreAF was not associated with an increased incidence of infective complications, re-exploration for bleeding, myocardial infarction, or perioperative blood transfusion.

Nine studies reported sufficient data for quantitative analysis of late mortality. ${ }^{4,8,10,12,18,20-23}$ Analysis of pooled data from these studies indicated that preAF was independently associated with late mortality (HR, 1.74; $95 \%$ CI, 1.42-2.13; $P<.001 ; \mathrm{I}^{2}=76 \%$ ).

Sensitivity analysis. Eight studies, ${ }^{9-12,17,18,22,23}$ involving a total of 381,218 patients, reported propensity-matched or adjusted ratios for the primary endpoint of perioperative

TABLE 3. Meta-analysis of the association of preoperative AF with outcomes after CABG (all studies)

\begin{tabular}{|c|c|c|c|c|c|}
\hline Outcome & No. of cohorts & OR/HR* & $95 \%$ CI & $P$ value & $\mathbf{I}^{2}(\%)$ \\
\hline Mortality & 13 & 1.64 & $1.29-2.09$ & $<.001$ & 54 \\
\hline Stroke & 11 & 1.50 & $1.06-2.11$ & .02 & 63 \\
\hline Acute renal failure & 11 & 1.50 & $1.23-1.83$ & $<.001$ & 48 \\
\hline Prolonged ventilation & 9 & 1.40 & $1.16-1.68$ & $<.001$ & 53 \\
\hline Reoperation & 5 & 1.22 & $1.07-1.40$ & .003 & 19 \\
\hline Infective complications & 7 & 1.30 & $0.98-1.73$ & .07 & 0 \\
\hline Re-exploration for bleeding & 7 & 1.05 & $0.72-1.53$ & .80 & 43 \\
\hline Myocardial infarction & 7 & 0.76 & $0.49-1.19$ & .24 & 0 \\
\hline Blood transfusion & 3 & 0.94 & $0.83-1.06$ & .31 & 0 \\
\hline Late mortality & 9 & 1.74 & $1.42-2.13$ & $<.001$ & 76 \\
\hline
\end{tabular}

$O R$, Odds ratio; $H R$, hazard ratio; $C I$, confidence intervals. *HR was the summary statistic for late mortality. For all other outcomes displayed, OR was the summary statistic. 
TABLE 4. Meta-analysis of the association of preoperative AF with CABG (adjusted studies)

\begin{tabular}{|c|c|c|c|c|c|}
\hline Outcome & No. of cohorts & OR/HR* & $95 \% \mathrm{CI}$ & $P$ value & $\mathbf{I}^{2}(\%)$ \\
\hline Mortality & 8 & 1.56 & $1.21-2.03$ & $<.001$ & 60 \\
\hline Stroke & 6 & 1.18 & $1.07-1.31$ & $<.001$ & 0 \\
\hline Acute renal failure & 6 & 1.43 & $1.13-1.82$ & .003 & 59 \\
\hline Prolonged ventilation & 6 & 1.34 & $1.09-1.65$ & .005 & 62 \\
\hline Reoperation & 3 & 1.24 & $1.09-1.42$ & .001 & 30 \\
\hline Infective complications & 5 & 1.33 & $0.99-1.79$ & .06 & 0 \\
\hline Re-exploration for bleeding & 3 & 1.32 & $0.79-2.22$ & .29 & 65 \\
\hline Myocardial infarction & 4 & 0.69 & $0.39-1.22$ & .20 & 0 \\
\hline Blood transfusion & 3 & 0.94 & $0.83-1.06$ & .31 & 0 \\
\hline Late mortality & 6 & 1.47 & $1.32-1.63$ & $<.001$ & 0 \\
\hline
\end{tabular}

$O R$, Odds ratio; $H R$, hazard ratio; $C I$, confidence intervals. *HR was the summary statistic for late mortality. For all other outcomes displayed, OR was the summary statistic.

mortality. The impact of preAF on early and late outcomes in this study cohort is provided in Table 4. A sensitivity analysis including only these studies still demonstrated a significant association between preAF and perioperative mortality (OR, 1.56; 95\% CI, 1.21-2.03; $P<.001$; $\mathrm{I}^{2}=60 \%$; Figure 1). PreAF also remained significantly associated with an increased risk of stroke, acute renal failure, prolonged ventilation, and reoperation for bleeding. Sensitivity analysis confirmed that preAF was a risk factor for late mortality (HR, 1.47 ; $95 \% \mathrm{CI}, 1.32-1.63 ; P<.001)$ and eliminated heterogeneity $\left(\mathrm{I}^{2}=0 \%\right)$.

Subgroup analysis: On-pump CABG. Eleven studies, ${ }^{8-12,17-19,21-23}$ involving a total of 384,666 patients, examined patients undergoing on-pump CABG surgery. Of these, 19,402 patients presented with preAF and 365,264 did not present with preAF. A summary of the impact of preAF on early and late outcomes in this study cohort is provided in Table 5. In subgroup analysis of on-pump CABG patients, preAF was associated with an increased risk of 4 perioperative complications including mortality (OR, 1.53; 95\% CI, 1.21-1.94; $P<.001$; $\mathrm{I}^{2}=50 \%$, Figure 2), acute renal failure (OR, 1.41; $95 \%$ CI, 1.17-1.69; $P<.001 ; \mathrm{I}^{2}=39 \%$ ), prolonged ventilation (OR, 1.34; 95\% CI, 1.13-1.60; $P<.001 ; \mathrm{I}^{2}=49 \%$ ), and reoperation for bleeding (OR, 1.23; 95\% CI, 1.04-1.46; $\left.P=.01 ; \mathrm{I}^{2}=38 \%\right)$. Pre $\mathrm{AF}$ was associated with late mortality (OR, 1.69; 95\% CI, 1.34-2.15; $P<.001$; $\mathrm{I}^{2}=81 \%$ ) following on-pump CABG.

Subgroup analysis: Off-pump CABG. Three studies, ${ }^{10,19,20}$ involving a total of 5322 patients, examined patients undergoing off-pump CABG surgery. Of these, 305 patients presented with preAF and 5027 did not present with preAF. A summary of the impact of preAF on early and late outcomes in this study cohort is provided in Table 6. In subgroup analysis of patients who underwent off-pump CABG, preAF was associated with an increased risk of perioperative mortality (OR, 2.75; 95\% CI, $1.35-5.59 ; P=.005, \mathrm{I}^{2}=18 \%$, Figure 3$)$. There was a trend toward an increased incidence of acute renal failure (OR, $\left.2.29 ; 95 \% \mathrm{CI}, 0.98-5.35 ; P=.06 ; \mathrm{I}^{2}=63 \%\right)$. PreAF was associated with an increased risk of late mortality (HR, $1.97 ; 95 \%$ CI, 1.26-3.08; $P=.003, \mathrm{I}^{2}=33 \%$ ) after off-pump CABG.

Subgroup analysis: Studies excluding Society of Thoracic Surgeons. A subgroup analysis was performed of studies excluding the large Society of Thoracic Surgeons study (Table 7). ${ }^{17}$ In this analysis, preAF was associated with an increased risk of perioperative mortality (OR,

\begin{tabular}{|c|c|c|c|c|}
\hline Study or Subgroup & log[Odds Ratio] & SE & Weight & $\begin{array}{l}\text { Odds Ratio } \\
\text { IV, Random, } 95 \% \mathrm{CI}\end{array}$ \\
\hline Ad 2009 & 0.262 & 0.041 & $26.2 \%$ & $1.30[1.20,1.41]$ \\
\hline Al-Sarraf 2012 & 0.693 & 0.371 & $7.9 \%$ & $2.00[0.97,4.14]$ \\
\hline Attaran (OPCABG) 2011 & 0.365 & 0.529 & $4.6 \%$ & $1.44[0.51,4.06]$ \\
\hline Attaran 2011 & 0.501 & 0.334 & $9.1 \%$ & $1.65[0.86,3.18]$ \\
\hline Banach 2008 & 1.012 & 0.245 & $13.1 \%$ & $2.75[1.70,4.45]$ \\
\hline Bramer 2010 & 0.723 & 0.331 & $9.2 \%$ & $2.06[1.08,3.94]$ \\
\hline Quader 2004 & -0.416 & 0.381 & $7.6 \%$ & $0.66[0.31,1.39]$ \\
\hline Rogers 2006 & 0.02 & 0.543 & $4.4 \%$ & $1.02[0.35,2.96]$ \\
\hline Saxena 2015 & 0.489 & 0.171 & $17.8 \%$ & $1.63[1.17,2.28]$ \\
\hline Total $(95 \% \mathrm{Cl})$ & & & $100.0 \%$ & $1.56[1.22,1.98]$ \\
\hline \multicolumn{5}{|c|}{$\begin{array}{l}\text { Heterogeneity: } \text { Tau }^{2}=0.06 ; \mathrm{Chi}^{2}=17.45, \mathrm{df}=8(\mathrm{P}=0.03) ; \mathrm{I}^{2}=54 \% \\
\text { Test for overall effect: } \mathrm{Z}=3.56(\mathrm{P}=0.0004)\end{array}$} \\
\hline
\end{tabular}

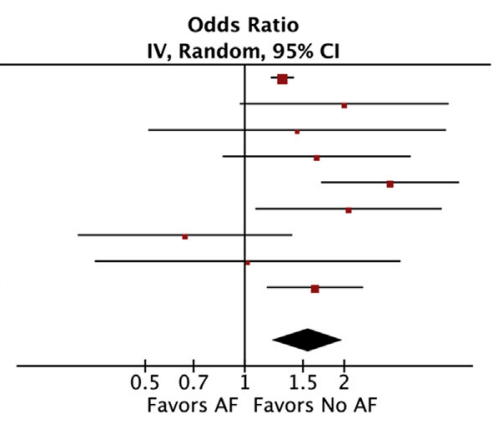

FIGURE 1. Meta-analysis of the association of preoperative AF with perioperative mortality after CABG (adjusted studies). SE, Standard error; $I V$, symptoms of heart failure at rest; $C I$, confidence interval; $O P C A B G$, off-pump coronary artery bypass grafting; $A F$, atrial fibrillation. 
TABLE 5. Meta-analysis of the association of preoperative AF with outcomes after on-pump CABG

\begin{tabular}{|c|c|c|c|c|c|}
\hline Outcome & No. of cohorts & OR/HR* & $95 \%$ CI & $P$ value & $\mathbf{I}^{2}(\%)$ \\
\hline Mortality & 10 & 1.53 & $1.21-1.94$ & $<.001$ & 50 \\
\hline Stroke & 9 & 1.22 & $0.98-1.51$ & .08 & 18 \\
\hline Acute renal failure & 9 & 1.41 & $1.17-1.69$ & $<.001$ & 39 \\
\hline Prolonged ventilation & 8 & 1.34 & $1.13-1.60$ & $<.001$ & 49 \\
\hline Reoperation & 4 & 1.23 & $1.04-1.46$ & .01 & 38 \\
\hline Infective complications & 6 & 1.31 & $0.98-1.76$ & .07 & 0 \\
\hline Re-exploration for bleeding & 5 & 1.13 & $0.75-1.72$ & .56 & 50 \\
\hline Myocardial infarction & 5 & 0.66 & $0.38-1.15$ & .15 & 0 \\
\hline Blood transfusion & 3 & 0.94 & $0.83-1.06$ & .31 & 0 \\
\hline Late mortality & 7 & 1.69 & $1.34-2.15$ & $<.001$ & 81 \\
\hline
\end{tabular}

$O R$, Odds ratio; $H R$, hazard ratio; $C I$, confidence intervals. *HR was the summary statistic for late mortality. For all other outcomes displayed, OR was the summary statistic

$1.74 ; 95 \%$ CI, 1.33-2.28; $P<.001$ ), acute renal failure (OR, $1.60 ; 95 \% \mathrm{CI}, 1.23-2.08 ; P<.001)$, and prolonged ventilation (OR, $1.52 ; 95 \% \mathrm{CI}, 1.15-2.00 ; P=.003)$. There was a clear association of preAF with late mortality (HR, 1.74; 95\% CI, 1.42-2.13).

Subgroup analysis: Excluding studies enrolling patients before 2000. A subgroup analysis of studies that recruited patients after 2000 is presented in Table 8. Four studies were excluded. ${ }^{8,12,22,23}$ In this analysis, preAF was associated with an increased risk of perioperative mortality (OR, 1.83; 95\% CI, 1.39-2.43; $P<.001$ ), stroke (OR, 1.54; $95 \%$ CI, 1.02-2.32; $P=.04)$, acute renal failure (OR, 1.52; 95\% CI, 1.20-1.93; $P<.001$ ), prolonged ventilation (OR, 1.44; 95\% CI, 1.14-1.83, $P=.002)$, reoperation for bleeding (OR, 1.19; 95\% CI, 1.13-1.26), and infective complications (OR, 1.42; 95\% CI, 1.02$1.97 ; P=.04)$. There was a clear association of preAF with late mortality (HR, $1.91 ; 95 \% \mathrm{CI}, 1.43-2.55$; $P<.001)$.

Publication bias. Both Egger's linear regression method $(P=.13)$ and Begg's rank correlation test $(P=.30)$ suggested publication bias was not an influencing factor when perioperative mortality was selected as an endpoint. Accounting for potentially missing studies using the imputed trim-and-fill method did not alter the result obtained for perioperative mortality.

\section{DISCUSSION}

The present meta-analysis demonstrated the preAF is an independent risk factor for poorer perioperative outcomes and reduced overall survival after CABG. There has been considerable debate among clinicians as to whether preAF independently predisposes patients to a poorer outcome or whether it is simply a marker of a more complex physiological milieu. Certainly, preAF is associated with age, cardiovascular comorbidities, impaired ventricular function, and critical perioperative state. $^{7,11}$

Nevertheless, our study demonstrated an independent association between preAF and poorer perioperative outcomes. A cumulative analysis of the 13 studies demonstrated that preAF increased the risk of perioperative mortality by $64 \%$ (OR, $1.64 ; 95 \%$ CI, $1.29-2.09 ; P<.001)$. Even when only studies that included propensity-matched or adjusted ratios were analyzed, preAF was independently associated with a $56 \%$ increase in the risk of perioperative mortality (OR, $1.56 ; 95 \% \mathrm{CI}, 1.21-2.03 ; P<.001)$. This is an important clinical finding particularly, given that

\begin{tabular}{|c|c|c|c|c|c|c|}
\hline Study or Subgroup & log[Odds Ratio] & SE & Weight & $\begin{array}{c}\text { Odds Ratio } \\
\text { IV, Random, } 95 \% \mathrm{Cl}\end{array}$ & $\begin{array}{r}\text { Odds R } \\
\text { IV, Random }\end{array}$ & $\begin{array}{l}\text { latio } \\
\text { l, } 95 \% \mathrm{CI}\end{array}$ \\
\hline Ad 2009 & 0.262 & 0.041 & $26.1 \%$ & $1.30[1.20,1.41]$ & & - \\
\hline Al-Sarraf 2012 & 0.693 & 0.371 & $7.5 \%$ & $2.00[0.97,4.14]$ & & \\
\hline Attaran 2011 & 0.501 & 0.334 & $8.7 \%$ & $1.65[0.86,3.18]$ & & \\
\hline Banach 2008 & 1.012 & 0.245 & $12.6 \%$ & $2.75[1.70,4.45]$ & & \\
\hline Boning 2015 & 0.451 & 0.497 & $4.8 \%$ & $1.57[0.59,4.16]$ & & \\
\hline Bramer 2010 & 0.723 & 0.331 & $8.8 \%$ & $2.06[1.08,3.94]$ & & \\
\hline Ngaage 2007 & -0.186 & 0.678 & $2.8 \%$ & $0.83[0.22,3.14]$ & & \\
\hline Quader 2004 & -0.416 & 0.381 & $7.2 \%$ & $0.66[0.31,1.39]$ & 8 & \\
\hline Rogers 2006 & 0.02 & 0.543 & $4.1 \%$ & $1.02[0.35,2.96]$ & & \\
\hline Saxena 2015 & 0.489 & 0.171 & $17.4 \%$ & $1.63[1.17,2.28]$ & & \\
\hline Total $(95 \% \mathrm{Cl})$ & & & $100.0 \%$ & $1.53[1.21,1.94]$ & & \\
\hline \multicolumn{5}{|c|}{$\begin{array}{l}\text { Heterogeneity: } \mathrm{Tau}^{2}=0.05 ; \mathrm{Chi}^{2}=18.04, \mathrm{df}=9(P=0.03) ; \mathrm{I}^{2}=50 \% \\
\text { Test for overall effect: } Z=3.58(P=0.0003)\end{array}$} & $\begin{array}{ccc}0.5 & 0.7 & 1 \\
\text { Favors AF }\end{array}$ & $\begin{array}{cc}1.5 & 2 \\
\text { Favors No }\end{array}$ \\
\hline
\end{tabular}

FIGURE 2. Meta-analysis of the association of preoperative AF with perioperative mortality after on-pump CABG. $S E$, Standard error; $I V$, symptoms of heart failure at rest; $C I$, confidence interval; $A F$, atrial fibrillation. 
TABLE 6. Meta-analysis of the association of preoperative AF with outcomes after off-pump CABG

\begin{tabular}{|c|c|c|c|c|c|}
\hline Outcome & No. of cohorts & OR/HR* & $95 \%$ CI & $P$ value & $\mathbf{I}^{2}(\%)$ \\
\hline Mortality & 3 & 2.75 & $1.35-5.59$ & .005 & 18 \\
\hline Stroke & 2 & 3.71 & $2.21-6.22$ & $<.001$ & 0 \\
\hline Acute renal failure & 2 & 2.29 & $0.98-5.35$ & .06 & 63 \\
\hline Prolonged ventilation & 1 & - & - & - & - \\
\hline Reoperation & 1 & - & - & - & - \\
\hline Wound infection & 1 & - & - & - & - \\
\hline Reoperation for bleeding & 2 & 0.72 & $0.27-1.95$ & .52 & 36 \\
\hline Myocardial infarction & 2 & 0.99 & $0.46-2.13$ & .99 & 0 \\
\hline Blood transfusion & 0 & - & - & - & - \\
\hline Late mortality & 2 & 1.97 & $1.26-3.08$ & .003 & 33 \\
\hline
\end{tabular}

$O R$, Odds ratio; $H R$, hazard ratio; $C I$, confidence intervals. *HR was the summary statistic for late mortality. For all other outcomes displayed, OR was the summary statistic.

previous cohort studies may have been underpowered to detect a clinical difference. .,12 $^{8}$

After mortality, the most significant sequela of AF is the increased risk of stroke. Our analyses demonstrated that preAF increased the risk of perioperative stroke by $50 \%$ (OR, $1.50 ; 95 \%$ CI, 1.06-2.11;P=.02). Off-pump CABG has been shown to reduce the incidence of perioperative stroke. ${ }^{24}$ Theoretically then, an off-pump revascularization strategy may reduce the incidence of stroke in patients with preAF. Attaran and colleagues ${ }^{10}$ performed a matched analysis which compared the outcomes of patients with and without preAF based on revascularization strategy (on-pump or off-pump). The authors demonstrated that, in patients undergoing on-pump CABG, preAF was associated with a significantly greater risk of stroke $(5.4 \%$ vs $1.6 \%, P<.001)$. In contrast, in patients undergoing off-pump CABG, preAF was not associated with stroke $(0 \%$ vs $0.5 \%, P>.99)$. Our analyses, however, demonstrated that preAF was associated with a greater than 3-fold increase in the risk of stroke in patients undergoing off-pump CABG (OR, 3.71; 95\% CI, 2.21-6.22; $P<.001)$. The optimal revascularization strategy for patients with preAF, therefore, remains unclear, and further prospective investigation is required. It must be noted that confounding factors may have influenced the observed outcomes. For example, the presence or absence of aortic crossclamping can influence the incidence of postoperative stroke. Unfortunately, we are unable to determine on a case-by-case basis precisely what proportion of the study population had aortic crossclamping.

PreAF also was associated with an independently increased risk of acute renal failure, prolonged ventilation, and reoperation for bleeding. Several mechanisms have been proposed to explain the association between preAF and poorer early outcomes. It has been suggested that reduced ventricular filling due to $\mathrm{AF}$ results in hypoperfusion of end organs such as the brain and kidneys, rendering patients susceptible to stroke and renal impairment. ${ }^{12}$ Encouragingly, however, we found no association between preAF and perioperative myocardial infarction. Moreover, our study showed no association between preAF and the rate of bleeding or blood transfusion between the 2 groups. This is an interesting observation, given that it is probable that a greater percentage of patients in preAF were on preoperative anticoagulants. The lack of a significant difference in the rate of bleeding may reflect good clinical management of preoperative anticoagulants in patients with preAF. It may also relate to good intraoperative management of coagulopathy/bleeding.

Our study demonstrated a strong association between preAF and late mortality. A cumulative analysis of the 9 studies showed that preAF increased the risk of late
Odds Ratio

\begin{tabular}{|c|c|c|c|c|}
\hline Study or Subgroup & log[Odds Ratio] & SE & Weight & IV, Random, $95 \% \mathrm{CI}$ \\
\hline Attaran (OPCABG) 2011 & 0.365 & 0.529 & $36.7 \%$ & $1.44[0.51,4.06]$ \\
\hline Boning (OPCABG) 2015 & 1.391 & 0.409 & $53.4 \%$ & $4.02[1.80,8.9$ \\
\hline Fukahara (OPCABG) 2010 & 1.351 & 1.117 & $9.9 \%$ & $3.86[0.43,34.4$ \\
\hline Total $(95 \% \mathrm{Cl})$ & & & $100.0 \%$ & $2.75[1.35,5.5$ \\
\hline
\end{tabular}

Odds Ratio IV, Random, $95 \% \mathrm{CI}$

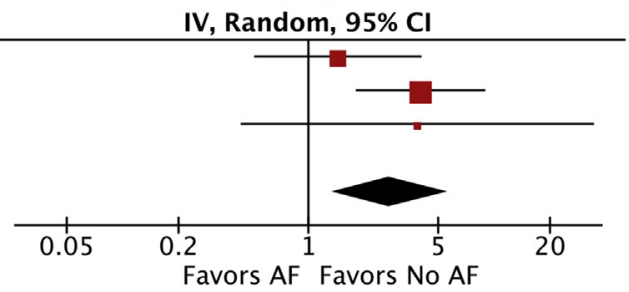

FIGURE 3. Meta-analysis of the association of preoperative AF with perioperative mortality after off-pump CABG. $S E$, Standard error; $I V$, symptoms of heart failure at rest; $C I$, confidence interval; $O P C A B G$, off-pump coronary artery bypass grafting; $A F$, atrial fibrillation. 
TABLE 7. Sensitivity analysis (excluding the STS study)

\begin{tabular}{|c|c|c|c|c|c|}
\hline Outcome & No. of cohorts & OR/HR* & $95 \% \mathrm{CI}$ & $P$ value & $I^{2}(\%)$ \\
\hline Mortality & 12 & 1.74 & $1.33-2.28$ & $<.001$ & 37 \\
\hline Stroke & 10 & 1.55 & $0.99-2.41$ & .05 & 60 \\
\hline Acute renal failure & 10 & 1.60 & $1.23-2.08$ & $<.001$ & 44 \\
\hline Prolonged ventilation & 8 & 1.52 & $1.15-2.00$ & .003 & 54 \\
\hline Reoperation & 4 & 1.30 & $0.98-1.73$ & .07 & 9 \\
\hline Wound infection & 7 & 1.30 & $0.98-1.73$ & .07 & 0 \\
\hline Reoperation for Bleeding & 7 & 1.05 & $0.72-1.53$ & .80 & 43 \\
\hline Myocardial infarction & 7 & 0.76 & $0.49-1.19$ & .24 & 0 \\
\hline Late mortality & 9 & 1.74 & $1.42-2.13$ & $<.001$ & 76 \\
\hline
\end{tabular}

mortality by up to $74 \%$ (HR, $1.74 ; 95 \%$ CI, $1.42-2.13$; $P<.001)$. Even when only propensity-matched or adjusted studies were analyzed, late mortality was increased by $47 \%$ (HR, 1.47; 95\% CI, 1.32-1.63; $P<.001$ ) with excellent homogeneity across studies $\left(\mathrm{I}^{2}=0\right)$. Our results were consistent with several of the studies included in the metaanalysis. Banach and colleagues ${ }^{18}$ evaluated 3000 patients who underwent isolated CABG and demonstrated that 3year survival was $20 \%$ lower in patients who had preAF $(71 \%$ vs $91 \%, P<.001)$. Rogers and colleagues ${ }^{12}$ similarly showed an absolute survival difference of $20 \%$ after 3 years (70\% vs $90 \%$; HR, 1.49 ; 95\% CI, 1.06-2.08; $P=.020)$.

The cause for increased late mortality in patients with preAF is multifactorial. First, preAF may predispose patients to thromboembolic or hemorrhagic events. ${ }^{25}$ Second, long-term AF may induce tachycardia-related cardiomyopathy. ${ }^{26}$ Third, long-term AF exacerbates congestive heart failure. ${ }^{27}$ Finally, potentially fatal anticoagulation-related complications are more common in patients with preAF due to the high use of warfarin. ${ }^{10}$

Given the implications of preAF on poorer perioperative and long-term outcomes, some investigators have advocated to role of adjunct strategies to treat AF. European guidelines suggest that all patients with symptomatic preAF who are undergoing cardiac surgery should be offered concomitant perioperative ablation (recommendation Class IIa, Level $\mathrm{A}^{28}$ ). They also recognize that surgical ablation should be considered in asymptomatic patients with preAF (Class IIb, Level C) ${ }^{28}$ Cheng and colleagues ${ }^{29}$ performed a meta-analysis of 33 studies including 10 randomized controlled trials (RCTs) that compared the outcomes of patients who underwent concomitant AF surgery with those that did not. The authors demonstrated a greater rate of sinus rhythm in RCT and non-RCT studies compared with cardiac surgery alone, and this effect remained robust over the long term (5 years). There is evidence that patients with successful sinus restoration had improved survival who were treated but remained in $\mathrm{AF}^{30}$ Concomitant left atrial occlusion has also been advocated as a treatment strategy to reduce stroke and perioperative mortality in patients with preAF, but further evidence is required to validate its clinical efficacy. ${ }^{30}$

Despite this evidence, the uptake of concomitant $\mathrm{AF}$ surgery has been inconsistent. An analysis of data from the Society of Thoracic Surgeons Adult Cardiac Surgery Database (2005-2010) showed that only $27.5 \%$ of patients undergoing $\mathrm{CABG}$ underwent ablation compared with $61.5 \%$ of patients undergoing mitral valve repair. ${ }^{31}$ As

TABLE 8. Subgroup analysis (excluding studies enrolling patients before 2000)

\begin{tabular}{|c|c|c|c|c|c|}
\hline Outcome & No. of cohorts & OR/HR* & $\mathbf{9 5} \% \mathbf{C I}$ & $P$ value & $\mathbf{I}^{2}(\%)$ \\
\hline Mortality & 9 & 1.83 & $1.39-2.43$ & $<.001$ & 60 \\
\hline Stroke & 8 & 1.54 & $1.02-2.32$ & .04 & 73 \\
\hline Acute renal failure & 8 & 1.52 & $1.20-1.93$ & $<.001$ & 62 \\
\hline Prolonged ventilation & 6 & 1.44 & $1.14-1.83$ & .002 & 69 \\
\hline Reoperation & 4 & 1.19 & $1.13-1.26$ & $<.001$ & 0 \\
\hline Wound infection & 4 & 1.42 & $1.02-1.97$ & .04 & 0 \\
\hline Reoperation for bleeding & 5 & 1.14 & $0.67-1.92$ & .63 & 54 \\
\hline Myocardial infarction & 5 & 0.76 & $0.45-1.30$ & .32 & 0 \\
\hline Late mortality & 9 & 1.97 & $1.43-2.55$ & $<.001$ & 84 \\
\hline
\end{tabular}

$O R$, Odds ratio; $H R$, hazard ratio; $C I$, confidence intervals. *HR was the summary statistic for late mortality. For all other outcomes displayed, OR was the summary statistic. 


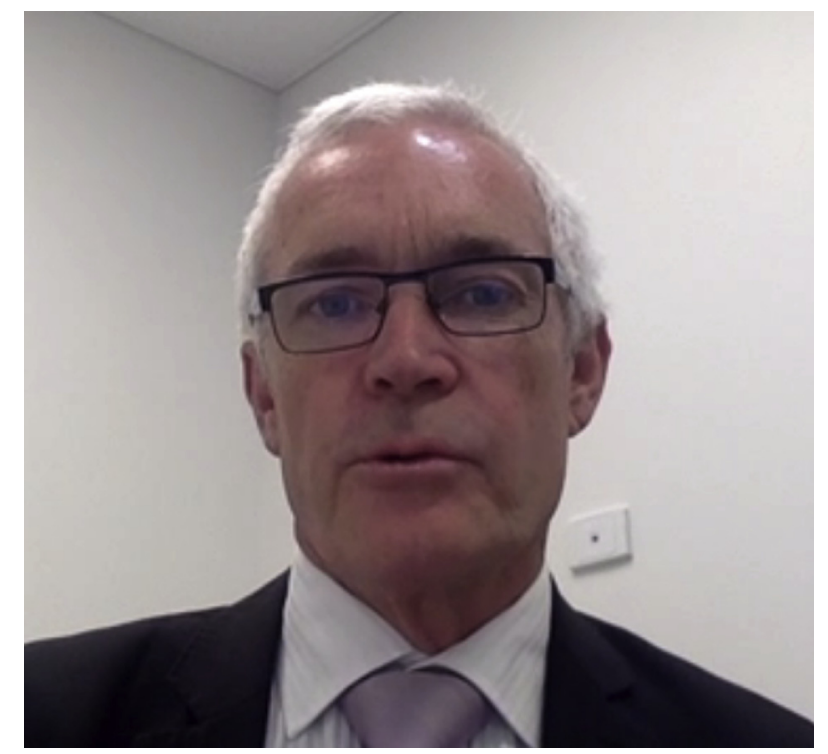

VIDEO 1. Professor Paul Bannon explaining the contribution of this study. Video available at: http://www.jtcvsonline.org/article/S00225223(17)32735-6/fulltext.

discussed by La Meir and colleagues, ${ }^{32}$ there are several reasons why concomitant ablation has not been universally adopted. First, there is a lack of large RCTs demonstrating the prognostic benefit of restoring sinus rhythm. Second, many surgeons do not believe that the additional technical complexity of AF ablation justifies the future benefits of sinus rhythm, particularly in patients who do not require an atriotomy. Overall, given the negative implications of preAF on both short- and long-term outcomes, there is a need for further investigate the impact of concomitant ablative strategy in patients with preAF undergoing CABG.

Our study has several limitations. First, all included studies were retrospective, observational reports. Second, considerable heterogeneity was detected in the analysis of several perioperative complications including mortality, stroke, prolonged ventilation, and acute renal failure. This may reflect differences in reporting standards, data collection, endpoint definitions, or perioperative management across institutions. For example, the incidence of preAF varied between studies. Although, to some degree, this reflects real variation across centers, it is likely that there were differences in screening practices across institutions. Third, due to the nature of the included studies, we could not determine the impact of the type or duration of preAF on clinical outcomes. Fourth, our analysis of off-pump CABG was limited by the small number of studies reporting clinical endpoints. Fifth, AF is associated with primary or secondary structural and physiologic derangements that can have a direct influence on outcomes after cardiac operations that would not be possible to account for in the study design of a meta-analysis. Finally, the analysis of early and late mortality was limited to an assessment of overall mortality rather than diseasespecific or event-specific mortality. Moreover, we were unable to gather sufficient data to evaluate the impact of preAF on late stroke, which is an important clinical endpoint.

In conclusion, this meta-analysis demonstrates that preAF is associated with poorer perioperative outcomes and reduced long-term survival after CABG. Our study does not prove causality, but it does suggest that there is need to evaluate the role of adjunct ablative strategies (Video 1).

\section{Conflict of Interest Statement}

Authors have nothing to disclose with regard to commercial support.

\section{References}

1. Sturm JW, Davis SM, O’Sullivan JG, Vedadhaghi ME, Donnan GA. The Avoid Stroke as Soon as Possible (ASAP) general practice stroke audit. Med J Aust. 2002; 176:312-6.

2. Feinberg WM, Blackshear JL, Laupacis A, Kronmal R, Hart RG. Prevalence, age distribution, and gender of patients with atrial fibrillation. Analysis and implications. Arch Intern Med. 1995;155:469-73.

3. Hart RG, Sherman DG, Easton JD, Cairns JA. Prevention of stroke in patients with nonvalvular atrial fibrillation. Neurology. 1998;51:674-81.

4. Saxena A, Dinh DT, Yap CH, Reid CM, Billah B, Smith JA, et al. Critical analysis of early and late outcomes after isolated coronary artery bypass surgery in elderly patients. Ann Thorac Surg. 2011;92:1703-11.

5. Ferguson TB Jr, Hammill BG, Peterson ED, DeLong ER, Grover FL. A decade of change-risk profiles and outcomes for isolated coronary artery bypass grafting procedures, 1990-1999: a report from the STS National Database Committee and the Duke Clinical Research Institute. Society of Thoracic Surgeons. Ann Thorac Surg. 2002;73:480-9; discussion 9-90.

6. Dinh DT, Lee GA, Billah B, Smith JA, Shardey GC, Reid CM. Trends in coronary artery bypass graft surgery in Victoria, 2001-2006: findings from the Australasian Society of Cardiac and Thoracic Surgeons database project. Med J Aust. 2008; 188:214-7.

7. Lloyd-Jones DM, Wang TJ, Leip EP, Larson MG, Levy D, Vasan RS, et al. Lifetime risk for development of atrial fibrillation: the Framingham Heart Study Circulation. 2004;110:1042-6.

8. Ngaage DL, Schaff HV, Mullany CJ, Sundt TM III, Dearani JA, Barnes S, et al. Does preoperative atrial fibrillation influence early and late outcomes of coronary artery bypass grafting? J Thorac Cardiovasc Surg. 2007;133:182-9.

9. Al-Sarraf N, Thalib L, Hughes A, Tolan M, Young V, McGovern E. Effect of preoperative atrial fibrillation on postoperative outcome following cardiac surgery. Cardiol Res Pract. 2012;2012:272384.

10. Attaran S, Saleh HZ, Shaw M, Bond L, Pullan MD, Fabri BM. Comparing the outcome of on-pump versus off-pump coronary artery bypass grafting in patients with preoperative atrial fibrillation. Interact Cardiovasc Thorac Surg. 2011;13: 288-92.

11. Saxena A, Kapoor J, Dinh DT, Smith JA, Shardey GC, Newcomb AE. Preoperative atrial fibrillation is an independent predictor of worse early and late outcomes after isolated coronary artery bypass graft surgery. J Cardiol. 2015;65:224-9.

12. Rogers CA, Angelini GD, Culliford LA, Capoun R, Ascione R. Coronary surgery in patients with preexisting chronic atrial fibrillation: early and midterm clinical outcome. Ann Thorac Surg. 2006;81:1676-82.

13. Moher D, Liberati A, Tetzlaff J, Altman DG. Preferred reporting items for systematic reviews and meta-analyses: the PRISMA statement. BMJ. 2009; 339:b2535.

14. Egger M, Smith GD, Schneider M, Minder C. Bias in meta-analysis detected by a simple, graphical test. BMJ. 1997;315:629-34.

15. Begg CB, Mazumdar M. Operating characteristics of a rank correlation test for publication bias. Biometrics. 1994;50:1088-101. 
16. Duval S, Tweedie R. Trim and fill: a simple funnel-plot-based method of testing and adjusting for publication bias in meta-analysis. Biometrics. 2000; $56: 455-63$.

17. Ad N, Barnett SD, Haan CK, O'Brien SM, Milford-Beland S, Speir AM. Does preoperative atrial fibrillation increase the risk for mortality and morbidity after coronary artery bypass grafting? J Thorac Cardiovasc Surg. 2009;137:901-6.

18. Banach M, Goch A, Misztal M, Rysz J, Zaslonka J, Goch JH, et al. Relation between postoperative mortality and atrial fibrillation before surgical revascularization-3-year follow-up. Thorac Cardiovasc Surg. 2008;56:20-3.

19. Boning A, Diegeler A, Hilker M, Zacher M, Reents W, Faerber G, et al. Preoperative atrial fibrillation and outcome in patients undergoing on-pump or off-pump coronary bypass surgery: lessons learned from the GOPCABE trial. Interact Cardiovasc Thorac Surg. 2015;20:74-8.

20. Fukahara K, Kotoh K, Doi T, Misaki T, Sumi S. Impact of preoperative atrial fibrillation on the late outcome of off-pump coronary artery bypass surgery. Eur J Cardiothorac Surg. 2010;38:366-72.

21. O'Neal WT, Efird JT, Davies SW, Choi YM, Anderson CA, Kindell LC, et al. Preoperative atrial fibrillation and long-term survival after open heart surgery in a rural tertiary heart institute. Heart Lung. 2013;42:442-7.

22. Quader MA, McCarthy PM, Gillinov AM, Alster JM, Cosgrove DM III, Lytle BW, et al. Does preoperative atrial fibrillation reduce survival after coronary artery bypass grafting? Ann Thorac Surg. 2004;77:1514-22; discussion 1522-4.

23. Bramer S, van Straten AH, Soliman Hamad MA, Berreklouw E, Martens EJ, Maessen JG. The impact of preoperative atrial fibrillation on early and late mortality after coronary artery bypass grafting. Eur J Cardiothorac Surg. 2010;38:373-9.

24. Deppe AC, Arbash W, Kuhn EW, Slottosch I, Scherner M, Liakopoulos OJ, et al. Current evidence of coronary artery bypass grafting off-pump versus on-pump: a systematic review with meta-analysis of over 16900 patients investigated in randomized controlled trialsdagger. Eur J Cardiothorac Surg. 2016;49: 1031-41.

25. Attaran S, Shaw M, Bond L, Pullan MD, Fabri BM. A comparison of outcome in patients with preoperative atrial fibrillation and patients in sinus rhythm. Ann Thorac Surg. 2011;92:1391-5.

26. Wang TJ, Larson MG, Levy D, Vasan RS, Leip EP, Wolf PA, et al. Temporal relations of atrial fibrillation and congestive heart failure and their joint influence on mortality: the Framingham Heart Study. Circulation. 2003;107:2920-5.

27. Stevenson WG, Stevenson LW. Atrial fibrillation in heart failure. $N$ Engl J Med. 1999;341:910-1.

28. Daubert JC, Saxon L, Adamson PB, Auricchio A, Berger RD, Beshai JF, et al 2012 EHRA/HRS expert consensus statement on cardiac resynchronization therapy in heart failure: implant and follow-up recommendations and management. Europace. 2012;14:1236-86.

29. Cheng DC, Ad N, Martin J, Berglin EE, Chang BC, Doukas G, et al. Surgical ablation for atrial fibrillation in cardiac surgery: a meta-analysis and systematic review. Innovations (Phila). 2010;5:84-96.

30. Lee R, McCarthy PM, Wang EC, Vaduganathan M, Kruse J, Malaisrie SC, et al Midterm survival in patients treated for atrial fibrillation: a propensity-matched comparison to patients without a history of atrial fibrillation. J Thorac Cardiovasc Surg. 2012;143:1341-51; discussion 1350-1.

31. Ad N, Suri RM, Gammie JS, Sheng S, O’Brien SM, Henry L. Surgical ablation of atrial fibrillation trends and outcomes in North America. J Thorac Cardiovasc Surg. 2012;144:1051-60.

32. La Meir M, Gelsomino S, Nonneman B. The problem with concomitant atria fibrillation in non-mitral valve surgery. Ann Cardiothorac Surg. 2014;3:124-9. 
TABLE E1. Quality assessment scores for individual studies

\begin{tabular}{|c|c|c|c|}
\hline \multirow[b]{2}{*}{ Study } & \multicolumn{3}{|c|}{ NOS quality assessment } \\
\hline & Selection of cohorts & Comparability of cohorts & Outcome assessment \\
\hline Ad and colleagues, $2009^{17}$ & $* * * *$ & $* *$ & $* *$ \\
\hline Al-Sarraf and colleagues, $2012^{9}$ & $* * *$ & $* *$ & $* *$ \\
\hline Attaran and colleagues, $2011^{10}$ & $* * * *$ & $* *$ & $* * *$ \\
\hline Banach and colleagues, $2008^{18}$ & $* * *$ & $* *$ & $* *$ \\
\hline Boning and colleagues, $2015^{19}$ & $* * *$ & - & $* *$ \\
\hline Bramer and colleagues, $2010^{23}$ & $* * * *$ & ** & $* * *$ \\
\hline Fukahara and colleagues, $2010^{20}$ & $* * *$ & * & $* *$ \\
\hline Ngaage and colleagues, $2007^{8}$ & $* *$ & * & $* *$ \\
\hline $\mathrm{O}^{\prime} \mathrm{Neal}$ and colleagues $2013^{21}$ & $* *$ & $*$ & $* * *$ \\
\hline Quader and colleagues, $2004^{22}$ & $* * * *$ & $* *$ & $* * *$ \\
\hline Rogers and colleagues, $2006^{12}$ & $* * * *$ & $* *$ & $* * *$ \\
\hline Saxena and colleagues, $2015^{11}$ & $* * * *$ & $* *$ & $* * *$ \\
\hline
\end{tabular}

The number of asterisks represents how many individual criterion within the subsection were fulfilled (from * to ****). NOS, Newcastle-Ottawa Scale. 


\begin{tabular}{|c|c|c|c|}
\hline \multirow[b]{2}{*}{ Study } & \multicolumn{3}{|c|}{ Critical appraisal of statistical analysis } \\
\hline & $\begin{array}{l}\text { Proportional } \\
\text { hazard } \\
\text { assumptions } \\
\text { verified? }\end{array}$ & $\begin{array}{c}\text { Form of statistical } \\
\text { adjustment }\end{array}$ & Variables accounted for in adjustment \\
\hline Ad and colleagues, $2009^{17}$ & NR & Multivariable regression models & $\begin{array}{l}\text { Age, BMI, LVEF, eGFR, sex, race, smoking status, } \\
\text { family history of CAD, diabetes, } \\
\text { hypercholesterolemia, HTN, CVA, IE, chronic lung } \\
\text { disease, immunosuppressive treatment, PVD, } \\
\text { previous PCI/CABG, triple-vessel disease, CHF, MI, } \\
\text { angina, NYHA IV, left main disease, cardiogenic } \\
\text { shock }\end{array}$ \\
\hline Al-Sarraf and colleagues, $2012^{9}$ & NR & Multivariable regression models & Logistic EuroSCORE \\
\hline Attaran and colleagues, $2011^{10}$ & NR & Propensity matching & $\begin{array}{l}\text { Age, BMI, LVEF, renal dysfunction, sex, smoking status, } \\
\text { diabetes, hypercholesterolemia, HTN, CVA, } \\
\text { respiratory disease, PVD, previous surgery, triple- } \\
\text { vessel disease, recent MI, angina class IV, logistic } \\
\text { EuroSCORE }\end{array}$ \\
\hline Banach and colleagues, $2008^{18}$ & NR & Multivariable regression models & NR \\
\hline Boning and colleagues, $2015^{19}$ & NA & Not performed & NA \\
\hline Bramer and colleagues, $2010^{23}$ & NR & Propensity matching & $\begin{array}{l}\text { Age, obesity/underweight, reduced LVEF, creatinine } \\
\text { clearance, sex, diabetes, HTN, CVA, COPD, PVD }\end{array}$ \\
\hline Fukahara and colleagues, $2010^{20}$ & NR & Multivariable regression models & $\begin{array}{l}\text { Age, hemodialysis, preoperative LVEF, sex, previous } \\
\text { CVA, PVD, new-onset postoperative AF }\end{array}$ \\
\hline Ngaage and colleagues, $2007^{8}$ & NR & Multivariable regression models & $\begin{array}{l}\text { Postoperative dialysis, diabetes, previous CVA, COPD, } \\
\text { MI, cardiomegaly }\end{array}$ \\
\hline O'Neal and colleagues $2013^{21}$ & NR & Multivariable regression models & $\begin{array}{l}\text { Age, race, sex, hypertension, previous CVA, CHF, } \\
\text { severity of CAD }\end{array}$ \\
\hline Quader and colleagues, $2004^{22}$ & NR & Propensity matching & $\begin{array}{l}\text { Age, BMI, renal insufficiency, LV dysfunction, sex, } \\
\text { diabetes, hypercholesterolemia, hypertension, } \\
\text { previous CVA, respiratory disease, PVD, previous } \\
\text { surgery, NYHA class, MI, ventricular arrhythmias }\end{array}$ \\
\hline Rogers and colleagues, $2006^{12}$ & NR & Multivariable regression models & $\begin{array}{l}\text { Age, BMI, renal dysfunction, sex, LVEF, smoking status, } \\
\text { NYHA class, diabetes, CHF, previous MI, Parsonnet } \\
\text { score, off-pump/on-pump CABG, severity of CAD, GI } \\
\text { disease, graft conduits used }\end{array}$ \\
\hline Saxena and colleagues, $2015^{11}$ & NR & Multivariable regression models & $\begin{array}{l}\text { Age, obesity, renal failure, LVEF, sex, smoking status, } \\
\text { diabetes, hypercholesterolemia, HTN, CVA, COPD, } \\
\text { PVD, previous cardiac surgery, CHF, triple-vessel } \\
\text { disease, recent MI, unstable angina, NYHA class, left } \\
\text { main stenosis, EuroSCORE }\end{array}$ \\
\hline
\end{tabular}

$B M I$, Body mass index; $L V E F$, left ventricular ejection fraction; $e G F R$, estimated glomerular filtration rate; $C A D$, coronary artery disease; $N R$, not reported; $H T N$, hypertension; $C V A$, cerebrovascular accident; $I E$, infective endocarditis; $P V D$, peripheral vascular disease; $P C I$, percutaneous coronary intervention; $C A B G$, coronary artery bypass grafting; $C H F$, congestive heart failure; $M I$, myocardial infarction; NYHA, New York Heart Association; euroSCORE, European System for Cardiac Operative Risk Evaluation; NA, not available; $C O P D$, chronic obstructive pulmonary disease; $A F$, atrial fibrillation; $L V$, left ventricular $G I$, gastrointestinal. 